\title{
Estudo do Fluxo Hídrico Subterrâneo nas Rochas Carsticas, na Porção Centro-Sul da Folha Cuiabá no Município de Nobres-(MT)
}

Raísa Brun Vendas ${ }^{1}$, Sergio Pytagoras Constantini ${ }^{1}$, Frederico Soares Dias ${ }^{2}$

1-Graduados Geologia UFMT, 2-Departamento de Geologia Geral-UFMT

Copyright 2014, SBGf - Sociedade Brasileira de Geofísica

Este texto foi preparado para a apresentação no VI Simpósio Brasileiro de Geofísica, Porto Alegre, 14 a 16 de outubro de 2014. Seu conteúdo foi revisado pelo Comitê Técnico do VI SimBGf, mas não necessariamente representa a opinião da SBGf ou de seus associados. É proibida a reprodução total ou parcial deste material para propósitos comerciais sem prévia autorização da SBGf.

\section{Resumo}

A área pesquisada situa-se ao SW do Cráton Amazônico, na zona externa da Faixa Paraguai, na região centro sul do Estado de Mato Grosso. A metodologia utilizada neste trabalho baseia-se princípios geofísicos da eletroresistividade, utilizando os métodos Sondagem Elétrica Vertical e Caminhamento Elétrico, ambas com arranjo schulumberger. Foram realizados quatro SEV's, sendo possível identificar quatro camadas distintas da base para o topo: rochas carbonáticas, camada argilosa, camada arenosa e uma cobertura pedológica do quaternário. Com o $\mathrm{CE}$ realizou-se quatro perfis de resistividade, que indicou a direção do fluxo subterrâneo. Realizou-se também um estudo de dolinas a partir de uma fotointerpretação na escala de 1.60.000, possibilitando observar que elas estão localizadas em duas direções diferentes e que equivale as direções das fraturas das rochas na região.

\section{Introdução}

A área estudada localiza-se na porção centro-sul do estado de Mato Grosso, compreendendo parte da Folha Cuiabá (SD. 21-Z-A). Localizada entre os vértices definidos pelas coordenadas UTM, 628000 - 650000 (E) e 8400000 - 8412000 (S). Foi cartografado aproximadamente $260 \mathrm{~km}^{2}$ na escala 1:60.000.

A área está localizada no município de Nobres, distante $160 \mathrm{~km}$ de Cuiabá. O Acesso é feito a partir de Cuiabá pela BR-251 percorrendo $16 \mathrm{~km}$ até a rotatória que dá acesso a MT - 351 em direção à represa do manso, passando a rotatória que dá acesso à comunidade de Bom Jardim, o acesso a área é realizado por estradas vicinais.

A área é dominada por metassedimentos proterozóicos do Grupo Alto Paraguai, composto pelas formações Araras (carbonatos), Raizama (arenitos) e Diamantino (pelitos), definidas por Alvarenga e Trompette (1992).

As áreas cársticas são de extrema importância, principalmente para: exploração de água subterrânea, por comportar poços de alta vazão; para o turismo, devido às cavernas e lagos característicos deste ambiente; e para a mineração, fornecendo matéria prima para as indústrias de cimento e fertilizantes etc. Além disso, as áreas cársticas estão sujeitas à instabilidades geotécnicas que podem colocar em risco pessoas e propriedades. Deste modo, estudos realizados em regiões cársticas têm se tornado cada vez mais importante.

O carste, no município de Nobres, já apresentou muitos problemas relacionados à instabilidade geotécnica (Albrecht, 1998) e tem sido utilizado para mineração, turismo e fornecimento de água subterrânea. Assim, estudos que venham a esclarecer o processo de carstificação e determinar as principais características deste carste, tem grande relevância como subsídio ao planejamento e ao desenvolvimento dessa região.

Ao longo deste trabalho serão apresentados os métodos utilizados e os resultados obtidos a partir de estudos geofísicos utilizando o método de elétroresistividade com Sondagem Elétrica Vertical e Caminhamento Elétrico.

A importância desta pesquisa esta no fato desta área ser de grande relevância para os recursos hídricos das regiões norte e centro-oeste do Brasil, já que ela abriga as nascentes do rio Arinos, da Bacia Amazônica, e nascentes que alimentam o rio Cuiabá, da Bacia Platina.

\section{Metodologia/ Problema Investigado}

Este trabalho foi dividido em quatro etapas principais: etapa preliminar; etapa de aquisição de dados; etapa de análise e tratamento dos dados; etapa de elaboração do texto.

A etapa preliminar foi constituída de um levantamento bibliográfico sobre a geologia da região, para se obter uma compreensão geológica prévia da área, posteriormente foi elaborado um mapa base preliminar através da analise de fotos aéreas da região na escala de 1:60000. Na etapa de aquisição de dados foram realizadas duas etapas de campos, a primeira entre os dias 24 e 28 de julho de 2013 e a segunda entre os dias 16 e 22 de outubro de 2013, na segunda etapa foram realizados os levantamentos geofísicos, descritos posteriormente. Em laboratório foi realizado o estudo das dolinas e o tratamento dos dados geofísicos.

A resistividade de um material segundo Kearey et al (2009), é dada como a resistência em ohms entre as faces opostas de um cubo unitário do material. Para um cilindro condutor de resistência $\mathbf{R}$, comprimento $\mathbf{L}$ e a área de seção transversal $\mathbf{A}$, a resistividade $\boldsymbol{\rho}$ é dada por: R.A/L.

A resistividade é uma característica física variável e sua leitura depende do meio físico exposto. Muitos dos minerais formadores de rocha não são bons condutores, a maioria é isolante e a corrente elétrica é conduzida através de uma rocha, essencialmente pela passagem de íons dissolvidos nas águas contidas nos poros. Portanto, 
quanto menor a quantidade de poros maior será a resistividade.

Para a realização deste trabalho foram utilizados os métodos de investigação de Sondagem Elétrica Vertical (SEV) e Caminhamento Elétrico (CE), em ambas as técnicas foram utilizadas 0 arranjo de eletrodos Schlumberger.

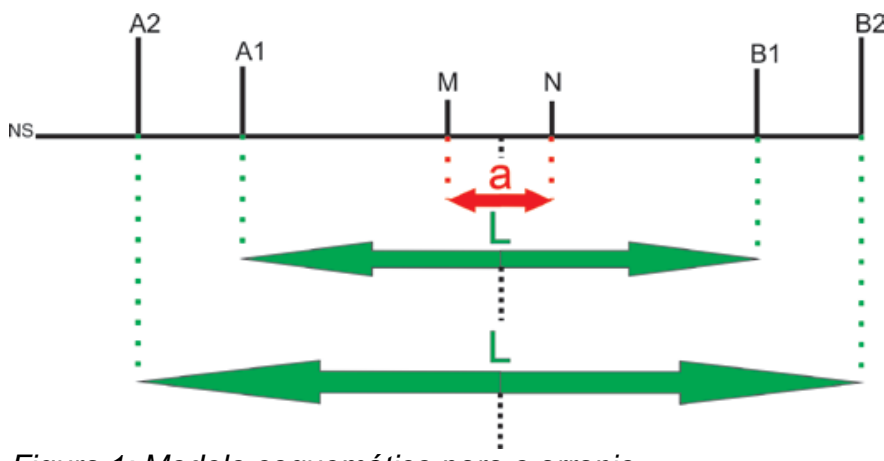

Figura 1: Modelo esquemático para o arranjo

Schlumberger em dois momentos A1/B1 e A2/B2. Onde

mantém o a fixo e o $L$ aumentando; NS: Nível de

Superfície.

A técnica da SEV consiste na investigação da variação vertical de resistividade aparente em uma seção geológica, podendo ser empregada na determinação da espessura e profundidade de pacotes sedimentares e rochas.

Esta técnica consiste em injetar corrente elétrica (I) no solo por dois eletrodos de corrente (A e B) e medir a diferença de potencial $(\Delta v)$ entre outros dois eletrodos denominados de eletrodos de potencial (M e $N$ ), localizados ao centro do arranjo, entre os eletrodos de corrente.

A técnica do CE consiste em investigar a variação horizontal de resistividade em um ou vários níveis de profundidade, obtendo uma leitura lateral da resistividade aparente em uma mesma profundidade, sendo que no centro são colocados os dois eletrodos de potencial (M e $\mathrm{N})$ e os dois eletrodos de corrente (A e B) nas extremidades do arranjo. $\mathrm{O}$ arranjo é montado e movimentam-se os quatro eletrodos na mesma direção com a mesma abertura.

Este trabalho teve como objetivo principal desenvolver estudos geofísicos que contribuam para o entendimento da direção do fluxo hídrico subterrâneo da região pesquisada, e com a analise desses estudos, determinar as direções principais encontradas.

\section{Resultados (Arial Bold, 9)}

Foram realizados quatro sondagens elétricas verticais e três caminhamentos elétricos. Segue os resultados destes ensaios.

Na SEV 1, o primeira nível identificado ocorre até a profundidade de 0,75 metros, com valor de resistividade aparente de 76 ohm.m e espessura de 0,75 metros. O segundo e terceiro níveis ocorrem entre 0,75 e 35,8 metros de profundidade, com resistividades aparentes de 1000 e de 680 ohm.m; e espessura somada de 35 metros. O quarto nível ocorre abaixo de 35,8 metros de profundidade, com resistividade aparente de 55 ohm.m. Esta SEV, teve abertura máxima de $\mathrm{AB} / 2$ de 120 metros, podendo investigar a uma profundidade máxima de 60 metros.

Na SEV 2, foram identificados sete níveis. Os dois primeiros ocorrem até a profundidade de 1,26 metros, com resistividades aparentes de 4100 a 9950 ohm.m. O terceiro, quarto e quinto níveis aparecem entre 1,26 e 71,3 metros de profundidade, com resistividades aparentes de 3725, 2120 e 4050 ohm.m; e espessura somada de 70 metros. O sexto nível aparece entre 71,3 e 158 metros de profundidade, sua resistividade aparente é de 64 ohm.m; e tem 87 metros de espessura. O sétimo e ultimo nível encontra-se a partir dos 158 metros de profundidade, com resistividade aparente que ultrapassa os 50000 ohm.m. Tal unidade foi interpretada como a rocha carbonática. O contraste de resistividade foi tão grande que não foi possível ajustar a curva pelo software IPI2wi. Esta SEV teve uma abertura $A B / 2$ de 485 metros, podendo investigar até 242,5 metros de profundidade.

Na SEV 3 foram identificados 9 níveis. Os dois primeiros ocorrem até 5,45 metros de profundidade, com resistividade de 462 a 1400 ohm.m. O terceiro nível aparece entre 5,45 e 12,9 metros de profundidade, sua resistividade aparente é de 4900 ohm.m; e tem 7,5 metros de espessura. Os níveis quatro e cinco aparecem entre 12,9 e 72,9 metros de profundidade, sua resistividade aparente varia de 1100 a 1600 ohm.m; e 36 metros de espessura. Os níveis seis, sete, oito e nove aparecem em profundidades a partir de 72,9 metros de profundidade, com resistividade aparente variando entre 150 e 850 ohm.m. Esta SEV teve abertura $A B / 2$ de 440 metros, podendo investigar até 220 metros de profundidade.

Na Sev 4 foram identificados 5 níveis. Os dois primeiros níveis tem profundidade até $2 \mathrm{~m}$, com resistividade de 900 a 11000 ohm.m). Os níveis três, quatro e cinco, ocorrem a partir de 2 metros de profundidade, com resistividade entre 16 e $90 \mathrm{ohm} . \mathrm{m}$, sendo que abaixo de 22 metros a resistividade cai, podendo representar sedimentos ainda mais argilosos. A partir de 52 metros a resistividade se eleva novamente. Esta SEV teve abertura $A B / 2$ de 290 metros, podendo investigar até 145 metros de profundidade.

$\mathrm{Na}$ área em estudo foram realizados três caminhamentos elétricos, sendo: um par de caminhamentos elétricos paralelos, com uma única profundidade de investigação; e um caminhamento elétrico com duas profundidades de investigação.

O par de caminhamentos elétricos paralelos teve direção N70E com $A B / 2=75$ e MN/2 = 15 sendo o passo das estações de 10 metros em ambos com 290 metros de linha de perfil. O caminhamento elétrico com duas profundidades de investigação teve como direção N30W sendo a primeira investigação com $A B / 2=75$ e $M N / 2=6$ 
e a segunda tendo $A B / 2=35$ e $M N / 2=6$ sendo o passo das estações de 10 metros e a linha com 60 metros de comprimento.

Através do estudo das dolinas foi possível caracterizar 36 dolinas tendo as direções N30W e N60E

\section{Discussão e Conclusões}

Neste capítulo será apresentada uma síntese dos estudos e resultados obtidos nessa pesquisa, que pretende contribuir para o entendimento hídrico subterrâneo de uma pequena parte da porção centro-sul do Estado de Mato Grosso em uma área dominada por metassedimentos do proterozóico.

Em seguida uma breve síntese do estudo das SEV's: na primeira SEV foram encontrados três níveis geoelétricos, sendo o topo uma camada pedológica, o segundo nível uma camada arenosa e o terceiro uma camada argilosa; A segunda SEV mostrou quatro níveis geoelétricos, no topo uma camada pedológica, o segundo nível uma camada arenosa, o terceiro nível uma camada argilosa e o último nível foi classificado como rocha carstica; $\mathrm{Na}$ terceira SEV tem-se quatro níveis geoelétricos, o primeiro uma camada pedológica, o segundo nível uma camada arenosa, o terceiro uma camada areno-argilosa e o quarto nível com uma camada argilosa; Na última SEV foi encontrado dois níveis geoelétricos, o primeiro com uma camada pedológica e no segundo uma camada argilosa. Correlacionando as quatro SEV's realizadas, é possível concluir que na região o subsolo encontra-se da base para o topo: rochas carbonáticas, camada sedimentar argilosa, camada sedimentar arenosa, e no topo uma cobertura pedológica de sedimentos inconsolidados do quaternário.

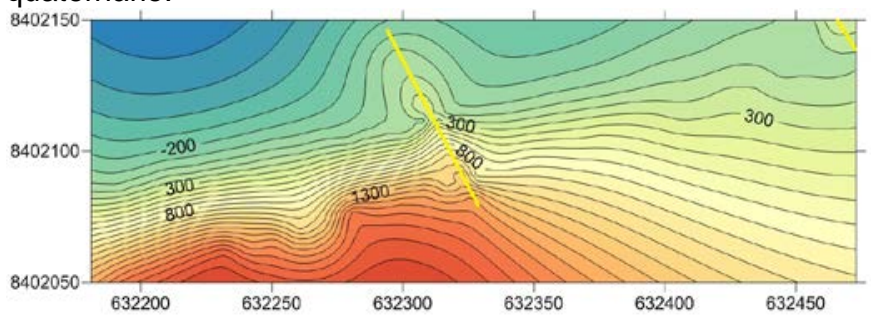

Figura 2: Mapa de contornos, em Amarelo as duas anomalias presentes na região.

Através do par de CE paralelos foi possível gerar o mapa de contornos apresentado acima, esse mapa indica a presença de duas anomalias de direção Noroeste, através do CE com duas profundidades foi possível gerar um perfil WSW-ENE onde se observa uma diminuição gradativa da resistividade à medida que se afasta da serra quartzítica, indicando que junto à encosta da serra o leito rochoso está mais raso, e vai aprofundando à medida que se afasta desta.

O estudo das dolinas pode ser relacionado à caracterização estrutural da área, com isso foi possível concluir que a direção em que elas se encontram equivale à direção das famílias de fraturas encontradas. Dito isto, pode-se afirmar que o fluxo hídrico da região está em parte relacionado ao fraturamento das rochas. A análise das dolinas, associada aos estudos geofísicos, indicam que a água subterrânea se move principalmente nas direções nordeste e noroeste, sendo que as dolinas possuem direções equivalentes as das fraturas encontradas nas rochas da região.

\section{Referências}

ALVARENGA, Carlos José Souza de \& TROMPETTE, R. Glacial influenced turbidite sedimentation in the uppermost Proterozoic and Lower Cambiran of the Paraguay Belt (Mato Grosso, Brazil. Palegogeography, Palaeoclimatotology, Palaecoelogy, n.92, p.85-105, 1992.

BRAGA, A. C. de O. Geofísica Aplicada, Módulo: Métodos Geoelétricos Aplicados nos Estudos de Captação e Contaminação das Águas Subterrâneas. Rio Claro, 207.

Kearey, P.; Brooks, M.; Hill, L., 2009. Geofísica de Exploração. Tradução Maria Cristina Moreira Coelho. São Paulo: Oficina do Texto, 438p. 